\title{
AVALIAÇÃO EXTERNA: IMPLICAÇÕES NA AVALIAÇÃO ESCOLAR
}

\author{
(1) ALINE ALVERNAZ' \\ (1) NÁDIA M. P. SOUZA" \\ (1) JOSÉ HENRIQUE"I
}

\begin{abstract}
Universidade Federal Rural do Rio de Janeiro (UFRRJ), Seropédica (RJ), Brasil; alinealvernaz@gmail.com
Universidade Federal Rural do Rio de Janeiro (UFRRJ), Seropédica (RJ), Brasil; nmpsouza@uol.com.br

Universidade Federal Rural do Rio de Janeiro (UFRRJ), Seropédica (RJ), Brasil; henriquejoe@hotmail.com
\end{abstract}

\section{RESUMO}

O objetivo desta pesquisa foi verificar as implicações da avaliação externa nas práticas de avaliação do processo ensino-aprendizagem nas escolas. A pesquisa é qualitativa e foram selecionados dez professores oriundos de duas escolas da rede estadual de ensino do Rio de Janeiro, sendo que uma delas alcançou as metas estabelecidas pela rede e recebeu bonificação salarial para os professores. Os dados foram coletados mediante entrevistas semiestruturadas. Os resultados revelam um engessamento das práticas avaliativas e uma supervalorização dos testes objetivos que reproduzem os moldes das avaliações externas. Há predominância dos aspectos quantitativos sobre os qualitativos e a caracterização do modelo essencialmente classificatório da avaliação escolar.

PALAVRAs-chaVe AVALIAÇÃo EXTERnA - AVALIAÇÃo ESCOLAR. 


\section{EVALUACIÓN EXTERNA: IMPLICACIONES EN LA EVALUACIÓN ESCOLAR}

\section{RESUMEN}

El objetivo de este estudio fue el de verificar las implicaciones de la evaluación externa en las prácticas de evaluación del proceso de enseñanza-aprendizaje en las escuelas. La investigación es cualitativa y han sido seleccionados diez docentes provenientes de dos escuelas de la red estadual de educación de Rio de Janeiro, siendo que una de ellas alcanzó las metas establecidas por la red y recibió bonificación salarial para los profesores. Los datos han sido recogidos por medio de entrevistas semiestructuradas. Los resultados revelan un endurecimiento de las prácticas evaluativas y una supervaloración de las pruebas objetivas que reproducen los moldes de las evaluaciones externas. Predominan los aspectos cuantitativos sobre los cualitativos y la caracterización del modelo esencialmente clasificatorio de la evaluación escolar.

PALABRAS CLAVE EVALUACIÓN EXTERNA • EVALUACIÓN ESCOLAR.

\section{EXTERNAL ASSESSMENT: IMPLICATIONS FOR SCHOOL ASSESSMENT}

\section{ABSTRACT}

This study aimed to verify the implications of external assessment in the assessment practices of the teaching-learning process in schools. For this qualitative study, ten teachers from two schools in the state education network of Rio de Janeiro were selected. One of the schools reached the goals established by the network and received a salary bonus for the teachers. Data were collected through semi-structured interviews. The results reveal a rigidifying of the assessment practices and an overvaluation of the objective tests that reproduce the patterns of the external assessments. There is a predominance of quantitative over qualitative aspects and the characterization of the essentially classificatory model of school assessment.

KEYWORDS EXTERNAL ASSESSMENT - SCHOOL ASSESSMENT. 


\section{INTRODUÇÃO}

A educação é um campo que está em um processo de contínuas mudanças e de reformas, a fim de acompanhar as demandas que se apresentam cotidianamente na sociedade. Nessa dinâmica, a avaliação educacional é sempre viva e presente, já que avaliar é uma ação que requer um compromisso político-pedagógico da comunidade escolar, tornando o processo avaliativo uma tarefa dialética, complexa, subjetiva e específica: dialética, porque deve considerar as contradições do processo educativo; complexa, pois demanda constante estudo e aprofundamento; subjetiva, pelo fato de cada professor se apropriar da avaliação de modo a adaptá-la à sua realidade, subsumindo-a a juízos e valores que os fazem do ensino-aprendizagem e de seus alunos; específica, visto que considera os contextos de cada escola, cada turma, cada aluno. A avaliação educacional, desse modo, deve ser um processo contínuo, global e constante.

Diante de inúmeras discussões sobre o processo avaliativo no cotidiano escolar, nota-se grande resistência em mudar metodologias há décadas configuradas, bem como em modificar a reprodução de modelos avaliativos padronizados. Sendo assim, carrega-se uma herança tradicional e positivista, pautada numa ação avaliativa classificatória como garantia do ensino de qualidade (HOFFMANN, 2006). Sob essa perspectiva, objetiva-se a busca dos índices, em geral quantitativos, presumivelmente associados à qualidade da educação.

É comum a utilização do termo "avaliocracia” (CORREIA, 2010; CORREIA; FIDALGO; FIDALGO, 2011) para caracterizar a posição dos processos avaliativos na rotina pedagógica das escolas. Terrasêca (2016) destaca que o termo pode ser associado à centralidade alcançada pela avaliação nos processos educativos à gestão de suas demandas.

Dos indicadores que procuram monitorar a qualidade da educação, destaca-se o Índice de Desenvolvimento da Educação Básica (Ideb), criado em 2007 pelo Instituto Nacional de Estudos e Pesquisas Educacionais Anísio Teixeira (Inep), que também estabelece metas para melhorias do ensino. O Ideb é calculado a partir dos dados sobre o fluxo escolar (aprovação) obtidos por meio do Censo Escolar ${ }^{1}$ e de médias de desempenho nas avaliações do Inep: o Sistema de Avaliação da Educação Básica (Saeb) e a Prova Brasil. O Ministério da Educação (MEC) estabeleceu o Ideb de 6,0 pontos (para os anos iniciais do ensino fundamental) como meta a ser alcançada até o ano de 2022, tendo como parâmetro os índices de países desenvolvidos.

Para alcançar o indicador estabelecido e monitorar o processo educativo no Brasil, a maioria dos estados (MACHADO; ALAVARSE, 2015) e municípios adotou 
avaliações externas às escolas, fenômeno que Afonso (2007) intitula "obsessão avaliativa”, devido à proliferação de sistemas avaliativos. Bertagna e Borghi (2018) destacam que 20 dos 27 estados brasileiros têm sistemas próprios de avaliação.

No estado do Rio de Janeiro (RJ), a Secretaria de Estado de Educação (Seeduc-RJ) adotou, a partir de 2008, o Sistema de Avaliação da Educação do Estado do Rio de Janeiro (Saerj), avaliação externa desenvolvida para promover a análise do desempenho dos alunos. O Saerj foi organizado para diagnosticar e monitorar a qualidade da educação nas escolas do estado, vislumbrando o alcance das metas estabelecidas pela própria secretaria, as quais tiveram como base o Ideb.

O Saerj foi composto por dois programas de avaliação: o Programa de Avaliação Diagnóstica do Desempenho Escolar e o Programa de Avaliação Externa. O primeiro ocorria bimestralmente e foi denominado Saerjinho (criado a partir de 2011). $O$ segundo era realizado no final de cada ano letivo, pelas turmas de $5^{\circ}$ e $9^{\circ}$ anos do ensino fundamental e pelas turmas de $3^{\mathrm{a}}$ série do ensino médio, popularmente chamado de Saerj, ou seja, pelas turmas de terminalidade do ensino regular. Vale destacar que os testes padronizados do Saerj e Saerjinho eram concebidos e organizados pelo Centro de Políticas Públicas e Avaliação da Educação (CAEd), ${ }^{2}$ órgão que pertence à Universidade Federal de Juiz de Fora (UFJF) que elabora e desenvolve programas de avaliação para mensurar o rendimento dos estudantes das escolas públicas.

Juntamente com os programas do Saerj, um conjunto de políticas públicas foi adotado pelo estado a fim de alcançar as metas previamente estipuladas pela Seeduc-RJ e, desse modo, elevar o Ideb da rede estadual de educação. Dentre essas políticas estão: as Matrizes de Referência da Avaliação Externa, que foram a base para a construção do Currículo Mínimo do estado; o Índice de Desenvolvimento da Educação do Estado do Rio de Janeiro (Iderj), que se apresenta como indicador de qualidade da rede estadual; a premiação dos alunos com os melhores resultados no Saerj; e a bonificação salarial dos professores cujas escolas alcançassem as metas do Iderj.

Essas ações estão intrinsecamente associadas aos procedimentos de avaliação em larga escala, na busca de índices, e, consequentemente, à suposta "qualidade" da educação escolar. No desenvolvimento dessas políticas implementadas pela rede estadual de ensino do Rio de Janeiro, observa-se que a avaliação do processo ensino-aprendizagem, a avaliação escolar, assume um novo objetivo, um novo rumo, um novo papel nas unidades escolares, reconfigurando as ações pedagógicas no espaço escolar (nesse caso, mais especificamente, a avaliação do processo ensino-aprendizagem realizada no cotidiano dos processos educativos). 
Observando o contexto da rede de ensino estadual do Rio de Janeiro, encontra-se a Avaliação Externa Saerj. Essa avaliação ditou o currículo escolar (Currículo Mínimo) por meio do qual professores receberam bonificação salarial. Outrossim, alunos foram premiados com notebooks e tablets, considerando os resultados dos testes padronizados de Língua Portuguesa e de Matemática e dos índices produzidos pelo fluxo escolar (aprovação/reprovação). Essa avaliação contou com a justificativa de monitoramento da qualidade de ensino oferecida, porém com um caráter regulador e de responsabilização dos agentes escolares pelo desempenho da educação da rede de ensino. Mediante esses apontamentos, o presente estudo objetiva verificar as implicações da Avaliação Externa Saerj na efetivação da avaliação escolar, refletindo sobre seus desdobramentos no campo educacional.

\section{METODOLOGIA}

A pesquisa tem cariz qualitativo, pois o objeto da investigação coloca como centro do enfoque lugares e pessoas, exigindo tratar a singularidade dos sujeitos e culturas institucionais como base para a compreensão do típico e geral (STAKE, 1983). Caracteriza-se, ainda, como do tipo casos múltiplos, na medida em que trata de conhecer a realidade de duas instituições, em princípio distintas, e a complexidade socioprofissional e pedagógica em função das condições geradas pela avaliação externa (YIN, 2001). A análise cruzada das instituições e, por conseguinte, de seus agentes permite conceber possibilidades de resultados tanto semelhantes quanto contrastantes, consoante às experiências vicárias dos sujeitos e correspondente análise interpretativa dos investigadores. Por fim, a pesquisa é descritiva porque, na essência, busca estabelecer um retrato descritivo do fenômeno observado, reportando os resultados aos diálogos estabelecidos com os sujeitos investigados (STAKE, 1983).

Dadas a vastidão e complexidade da rede estadual de ensino do Rio de Janeiro, bem como o grande número de escolas abrangidas, buscamos compreender os fatos, tomando como base duas escolas de um município da Baixada Fluminense, RJ. O critério de seleção das escolas está ligado ao alcance das metas estabelecidas pela Seeduc-RJ e regulamentadas no Decreto n. 5.092, de 28 de abril de 2014 (RIO DE JANEIRO, 2014), sendo uma escola que alcançou as metas do Iderj e seus docentes receberam a bonificação salarial (A) e uma escola que não atingiu as metas e não foi contemplada com a bonificação salarial (B). Essa opção visou a contrastar contextos de escolas e agentes em diferentes condições, a fim de analisar as implicações das políticas de avaliação externa implementadas. Dessa forma, adotamos como base os dados publicados em 2013 no website da Seeduc-RJ, visto que foram os últimos divulgados até o período desta pesquisa. 
Para além das questões de alcance de metas e de bonificação salarial dos professores, é necessário salientar algumas características do contexto das unidades escolares que compõem este estudo.

A Escola A era relativamente pequena, com 9 salas de aula, acomodando 18 turmas com aproximadamente 30 alunos, atendendo apenas ao ensino médio, contando com um quadro pleno de professores. Foi fundada há mais de 45 anos e estava situada em um local de fácil acesso e centralizado do município, com urbanização adequada no entorno.

É importante destacar que a Escola B é um Centro Integrado de Educação Pública $(\text { Ciep })^{3}$ com grande espaço físico, que, naquele momento, ainda tinha turmas de segundo segmento do ensino fundamental e o ensino médio. Vale ressaltar que a Seeduc-RJ é responsável pelas escolas que oferecem, em prioridade, a modalidade de ensino médio, de acordo com a Lei n. 4.528, de 28 de março de 2005 (RIO DE JANEIRO, 2005). No entanto, a escola vivia um momento de grande evasão escolar; atendia a 16 turmas, com baixa frequência, apresentando alta rotatividade de professores, com carência de profissionais de algumas disciplinas, o que era uma realidade comum, segundo o departamento de pessoal da escola. Situava-se no alto de uma ladeira, próxima ao centro do município, com sérias questões de urbanização em seu entorno.

Em cada uma das unidades escolares, selecionaram-se cinco docentes do ensino médio, sendo um de cada uma das áreas de conhecimento estabelecidas na Resolução n. 24, de 30 de janeiro de 2012, do Conselho Nacional de Educação/Câmara de Educação Básica (BRASIL, 2012), que define as Diretrizes Curriculares Nacionais para o Ensino Médio (Linguagens, Matemática, Ciências da Natureza e Ciências Humanas), além do professor de Educação Física.

A opção pelo ensino médio deu-se pelo fato de esse nível de ensino estar sob a responsabilidade da rede estadual de educação. Outrossim, a seleção do professor de Educação Física se justifica pela identidade da pesquisadora como profissional da área e, nessa condição, houve interesse em conhecer os procedimentos avaliativos na disciplina, ainda que essa não seja contemplada nas avaliações externas. Dessa maneira, a Educação Física apresenta parâmetros e critérios de avaliação, em geral, distintos das disciplinas mais valorizadas no currículo escolar.

Recorreu-se a entrevistas semiestruturadas para análise do discurso dos professores ante a questões que envolviam a avaliação escolar e a avaliação externa Saerj, a fim de identificar sua aplicação didático-pedagógica. O roteiro da entrevista

3 Os Cieps começaram a ser implementados durante os anos 1980 e 1990, em dois períodos governamentais (1983-1986 e 1991-1994). Disponível em: http://www.scielo.br/pdf/cp/n119/n119a08.pdf. Acesso em: jun. 2015. 
semiestruturada foi concebido a partir de uma matriz teórica construída com base em publicações problematizadoras do tema avaliação externa e avaliação escolar e, posteriormente, submetido a um teste-piloto com docentes lotados em uma instituição que não compôs essa amostra. As entrevistas com os sujeitos da amostra foram realizadas em julho de 2015 e registradas por meio de gravação de áudio. Todas as entrevistas foram transcritas e analisadas com o suporte do software MAXQDA ${ }^{\odot}{ }^{4}$

\section{DISCUSSÃO}

As escolas investigadas adotavam normativas e modelos de avaliação escolar baseados na Portaria Seeduc/Sugen n. 419, de 27 de setembro de 2013 (RIO DE JANEIRO, 2013), expedida pela Seeduc-RJ, que conceituava, organizava e sugeria que a avaliação fosse desenvolvida numa perspectiva qualitativa e formativa, com base em instrumentos diversificados. Essa portaria atualizou os pressupostos avaliativos adotados para toda a rede estadual, estabelecendo as normas de avaliação do desempenho escolar. Com a finalidade de uma depreensão do conteúdo da portaria, de maneira apurada por parte de gestores e professores, a Seeduc-RJ publicou o manual de orientações para operacionalização da portaria, o qual pormenorizava, sugeria e fundamentava a forma de proceder à avaliação escolar.

No texto da portaria, destaca-se o trecho relativo aos instrumentos de avaliação que efetivam a prática avaliativa da rede.

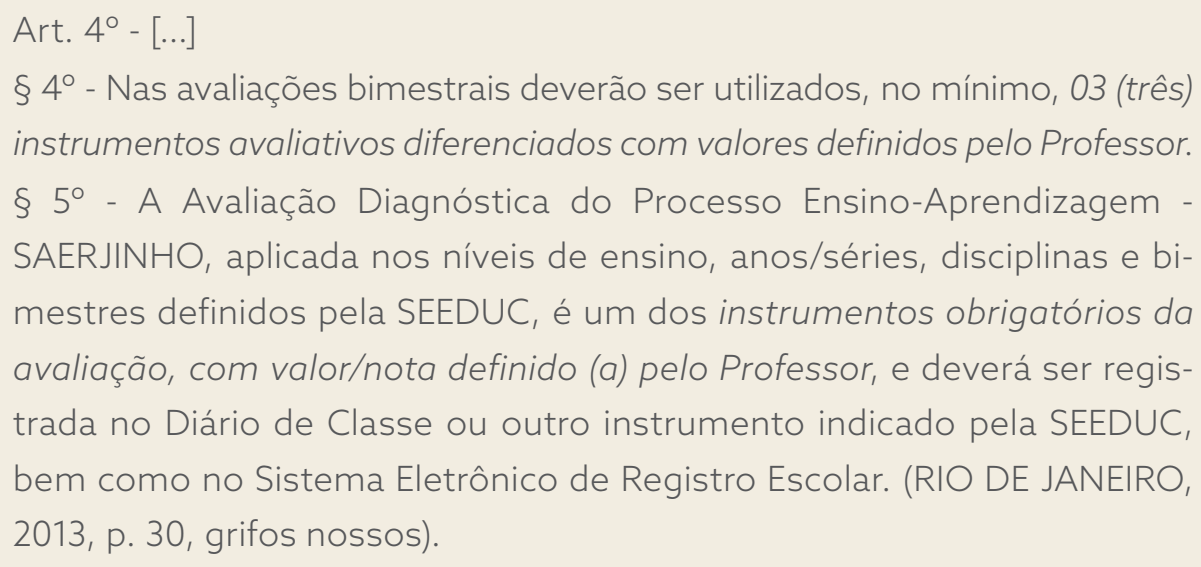
instrumentos avaliativos diferenciados com valores definidos pelo Professor. $\S 5^{\circ}$ - A Avaliação Diagnóstica do Processo Ensino-Aprendizagem SAERJINHO, aplicada nos níveis de ensino, anos/séries, disciplinas e bimestres definidos pela SEEDUC, é um dos instrumentos obrigatórios da avaliação, com valor/nota definido (a) pelo Professor, e deverá ser registrada no Diário de Classe ou outro instrumento indicado pela SEEDUC, bem como no Sistema Eletrônico de Registro Escolar. (RIO DE JANEIRO, 2013, p. 30, grifos nossos).

A portaria propunha que as avaliações bimestrais fossem compostas de, pelo menos, três instrumentos de avaliação, cabendo ao professor a eleição desses e o estabelecimento de sua proporcionalidade na composição da nota discente. Imputava, também, a adoção do Saerjinho como instrumento obrigatório na composição da avaliação escolar, incumbindo o professor sobre a decisão de seu peso proporcional no conjunto de avaliações de cada bimestre. 
Com o suporte dessa portaria, as unidades escolares investigadas elegeram a maneira como realizariam a avaliação escolar de seus alunos, formulando sua normativa de avaliação e elegendo os instrumentos adequados para sua efetivação, designando o peso para a composição da nota, resultado final da avaliação.

As duas escolas investigadas apresentaram normativas de avaliação idênticas, pautadas em testes teóricos que reproduziam o modelo da avaliação externa. Para compor a avaliação, as escolas adotaram um modelo comum a ser utilizado por todas as disciplinas da unidade escolar. Os instrumentos adotados eram o Provão, o Saerjinho e outros instrumentos avaliativos eleitos individualmente pelos professores. Na lógica da normativa identificada nas escolas, o Provão era uma avaliação teórica com questões objetivas e cartão-resposta reproduzindo o modelo Saerj, cujo peso era de $50 \%$ da nota discente. A construção desse instrumento era realizada de maneira coletiva, não integrada, em que o coordenador pedagógico e/ou diretor se responsabilizavam por coletar as questões com os docentes para organizá-las em um documento único de teste. Cada disciplina tinha um número determinado de questões em que todas eram contempladas, até mesmo aquelas não contidas no Saerj. Após a resolução das questões, o Provão era corrigido e o aluno recebia uma nota que cabia a todas as disciplinas igualmente. Esse modelo de teste adotado apresenta uma clara maneira de desenvolvimento de um preparatório para a resolução de provas objetivas, nesse caso, o Saerj.

Como previa a portaria, o Saerjinho constituía instrumento de avaliação obrigatório, porém sem mencionar seu peso na nota discente, o qual era atribuído pelo professor. Ainda assim, encontrou-se a adoção do peso $20 \%$ em ambas as escolas investigadas. Contemplando a normativa institucionalizada, as escolas contabilizavam as notas do Saerjinho nos três primeiros bimestres e o Saerj no quarto bimestre letivo. Esse acordo padronizado demonstra um critério generalizado sem a devida criticidade, haja vista que o fato se configurou em ambas as escolas. Os 30\% restantes eram designados pelos professores, que elegiam a maneira mais adequada para sua avaliação, cabendo a esses usar sua "liberdade avaliativa" nessa parcela da nota discente.

Em síntese, a avaliação escolar dos alunos, nas duas escolas investigadas, representava as proporções relativas aos 50\% do Provão, 20\% do Saerjinho e 30\% de outros instrumentos avaliativos designados pelos professores.

Constatou-se que, apesar de as escolas apresentarem diferentes localizações, comunidades, professores e gestores, ainda assim, os critérios de avaliação eram idênticos em ambas. Ainda que a normativa da Seeduc-RJ imputasse a obrigatoriedade do Saerjinho, a avaliação escolar foi quantificada e constituída da mesma maneira. $E$ isso foi possível observar em muitas outras escolas da rede de ensino daquela região. Havia uma cultura avaliativa que se configurava nas cercanias da avaliação externa adotada pela rede estadual de educação fluminense. 
Dessa forma, o Saerjinho torna-se o elemento de controle e balizador da normativa de avaliação das escolas investigadas. Um instrumento de avaliação obrigatório nos moldes do Saerj torna-se base para que os demais instrumentos sejam construídos (controle). Assim, seus resultados, juntamente com os demais instrumentos (Provão e outros), geram os índices de fluxo que compõem o indicador de qualidade que está associado ao pagamento do bônus. Como aponta Martins (2015), a partir do instante em que a obrigatoriedade do modelo de avaliação Saerjinho é legitimado e veicula a remuneração salarial variável, a bonificação, passa a impor limites à prática educativa dos professores (balizador).

Quanto aos professores da Escola A, observou-se que a avaliação escolar é constituída com a utilização de provas objetivas (Provão e Saerjinho), atividades cotidianas e cumprimento de tarefas. Parecem compreender e conceber a avaliação como processo, porém efetivando-a como produto final e incorporando os testes objetivos:

Eu vou construindo a avaliação dos meus alunos no dia a dia, através do comportamento, do cumprimento de tarefas e com testes, provas e trabalhos. (Professor de Língua Portuguesa, Escola A).

Eu uso a prova porque a escola adota a prova. O teste eu normalmente faço em sala com eles [...]. Avalio o aluno um por um e os trabalhos eles vão fazendo em sala. Então, praticamente a nota final é obtida de acordo com a produtividade que o aluno teve em sala. [...] minha avaliação é muito de acordo com a produtividade do aluno em sala. Eu não acredito muito em avaliação em uma folha só não. Que vem só uma folha com questões. Então eu avalio muito mais o aluno na sala de aula de acordo com a produtividade contínua dele. (Professor de Química, Escola A).

Essa assunção de avaliação como processo recorrente aparece associada a um maior número de instrumentos e procedimentos avaliativos para gerar a nota final do aluno:

Eu avalio através do comportamento, do cumprimento de tarefas e com testes, provas e trabalhos. (Professor de Língua Portuguesa, Escola A).

[...] são trabalhos. São avaliações feitas em sala, provas e testes. $E$, às vezes, dependendo do bimestre tem projeto. (Professor de Matemática, Escola A).

[...] basicamente caderno, avaliação de participação, enfim. Com exercícios e tal. Trabalho que todo bimestre rola [...]. E para o ensino médio a gente vai mais nos seminários. [...] E avalia prova. (Professor de Geografia, Escola A).

Diante do posicionamento dos professores da Escola $A$ sobre a normativa de avaliação, há um destaque para o processo de avaliação do dia a dia - avaliações 
em sala, caderno, participação -, recorrente nas perspectivas apresentadas. Nota-se, nas preocupações dos professores de Língua Portuguesa, Geografia e História, a sensibilidade com uma avaliação que se constrói cotidianamente. Existem a preocupação e a atenção em acompanhar o processo evolutivo de aprendizagem dos alunos pelas atividades que se desenvolvem em sala de aula. No entanto, a prova é parte da normativa e instrumento de avaliação obrigatório (Saerjinho). Assim, o professor a incorpora na sua avaliação do processo ensino-aprendizagem nos moldes instituídos.

A professora da disciplina de Educação Física apresenta uma avaliação diretamente relacionada à nor mativa da escola. Mesmo que sua disciplina não compusesse as avaliações externas, a docente não mencionou procedimentos que valorizassem o acompanhamento do desenvolvimento educativo dos alunos de forma sistemática, como ocorreu nas demais disciplinas, não demonstrando clareza da postura avaliativa para além dos testes.

Bom, na rede estadual já tem a questão das três avaliações. Obrigatórias. Então aqui na escola nós temos a avaliação que se chama Provão. A gente também utiliza a nota do Saerj, também uma avaliação obrigatória. E as outras avaliações ficam por conta do professor. Uma prova, uns trabalhos e vai passando [...]. (Professora de Educação Física, Escola A).

Destaca-se, aqui, que a cultura avaliativa instalada engloba, inclusive, as disciplinas que não estão contempladas na avaliação externa. Tacitamente, o modelo instituído é incorporado por todas as disciplinas, reconfigurando a avaliação escolar nos moldes dos testes padronizados.

Observando o posicionamento dos professores da Escola B em relação à normativa de avaliação, foi possível identificar que consideram a avaliação escolar de uma maneira paralela ao processo de ensino, mas, ainda assim, destacam os testes normativos como seus principais instrumentos de avaliação, associados à preocupação com a quantificação do desempenho:

Minhas avaliações são através do Provão, do Saerj e participação. Em alguns bimestres é projeto, participação e comportamento. (Professor de Língua Portuguesa, Escola B).

[...] bom, a gente usa os instrumentos básicos, prova, teste, trabalho. Mas a gente envolve pesquisa, envolve até como avaliação o dia a dia na sala, a participação do aluno. (Professor de Matemática, Escola B).

As avaliações, no meu caso, são feitas paralelamente. Então eu acabo utilizando o recurso da prova escrita, mas eu faço atividades em sala de aula e ao longo do bimestre. Depois eu vou somar essas avaliações em sala de aula e no final fecha a média juntamente com a prova. (Professor de História, Escola B). 
Geralmente eu uso uma avaliação do trabalho que é feito em sala de aula. De trabalho em sala de aula eu chamo caderno, conteúdo que é passado em sala e exercícios em geral [...] por mais que a gente queira fazer uma avaliação subjetiva para o aluno, a gente tem que ter uma avaliação que seja quantitativa, em números. Então minha avaliação parte também da questão da participação do aluno, mas ela tem que ter uma quantificação por essa participação. (Professor de Biologia, Escola B).

Os professores da Escola B apresentam uma regularidade na escolha dos instrumentos de avaliação, seguindo o padrão normativo-escolar de avaliação que não varia em função das disciplinas investigadas. Também há destaque para as atividades cotidianas, a participação e as atividades em sala como elementos de avaliação a serem considerados, o que pode demonstrar uma necessidade/falta de engajamento dos alunos nas atividades desenvolvidas. No entanto, os professores se mostraram vinculados à necessidade de quantificação, que acaba se planificando na forma de teste escrito, ratificando o modelo da avaliação externa.

Marinho, Leite e Fernandes (2013) destacam uma pesquisa realizada sobre os instrumentos de avaliação adotados em duas unidades escolares, apontando o processo que denominaram "testinite". Nesse processo, professores utilizam testes escritos, em diferentes apresentações (prova, trabalho, teste, pesquisa), como principal meio de construir as avaliações discentes, apesar de mencionarem o uso de outros instrumentos de avaliação. A necessidade de quantificação inibe a avaliação que valorize mais o processo e a utilização de instrumentos não baseados em testes objetivos. Apesar de lançar mão de alternativas avaliativas, o peso das avaliações estará no teste escrito, objetivo e normatizado, como relatado pela professora de Biologia da Escola $B$.

Por mais que a gente queira fazer uma avaliação subjetiva pro aluno, a gente tem que ter uma avaliação que seja quantitativa, em números. (Professora de Biologia, Escola B).

Ainda na Escola B, o professor da disciplina de Educação Física apresenta sua avaliação no molde da normativa adotada pela escola, sem clareza da utilização de seus instrumentos. Sendo uma disciplina teórico-prática, o professor não deixa claro ao que e a quem se destina a prova, deixando antever ausência de critérios e rotinas avaliativas. Além disso, deixa dúvida quanto à propriedade de suas avaliações, na medida em que, para "ajudar" os alunos, condiciona sua avaliação ao resultado obtido nas avaliações externas.

É dividido em três partes: provas, trabalhos e outros. Provas (prova prática) [...] é a que eu dou para aqueles alunos que participam, vale como prova. E para aqueles que não participam eu dou uma prova (prova teórica). 
Trabalho só para aqueles que não participam das aulas de Educação Física. E outros é uniforme que a gente pede para fazer as aulas. E agora, com relação ao Saerjinho, não tem participação nenhuma porque minha avaliação não entra no Saerjinho. [...]. Nós temos uma lista de todas as pessoas que fazem, a lista dos alunos que fizeram o Saerj. Aí é até um modo de ajudá-los né, porque geralmente não fazem a aula prática, aí eu vejo que tirou uma boa nota no Saerjinho/Saerj [...], eu dou a pontuação para esse aluno. (Professor de Educação Física, Escola B).

A Educação Física adota a mesma normativa de avaliação nas escolas A e B, considerando o Saerj/Saerjinho um instrumento de avaliação, mesmo que seus conteúdos não fossem contemplados. Portanto, o professor acaba por avaliar o aluno pelo desempenho em outras áreas disciplinares. $\mathrm{O}$ mesmo princípio se atribui às demais disciplinas não contempladas na avaliação externa e, ainda assim, o aluno é avaliado pela sua presença e pela realização da prova, com a justificativa de a disciplina estar contemplada nas áreas de conhecimento das quais estão subdivididos os testes e incentivo à sua participação. Esse processo denota uma grande burla da avaliação do processo ensino-aprendizagem, uma supervalorização dos testes objetivos, gerando uma incoerência consistente no processo educativo.

A necessidade de pontuar o aluno com uma avaliação que não contempla todas as disciplinas, resumindo a uma maneira de incentivar o comparecimento do aluno para a realização das avaliações externas, é uma postura que não condiz com a ação avaliativa responsável, formativa e da qual emerge uma concepção de avaliação burocratizada e sem valor ético e/ou educativo, utilizando-a apenas como instrumento e parâmetro para medida e quantificação. Assim, essa concepção não considera a avaliação dialógica, formativa e qualitativa.

Hadji (2001) também afirma que o ato de medir não consolida um processo de avaliação, mas apenas apresenta um conjunto parcial de informações sobre os processos educativos. Assumir a lógica dos exames como determinante da avaliação escolar, do processo ensino-aprendizagem ou do desempenho dos alunos não constrói uma visão adequada dos processos educativos, tampouco contribui para a reorientação da prática pedagógica. Entretanto, esse "incentivo" incide diretamente no número de alunos que participam das atividades de avaliação externa na escola, um dos critérios de análise do programa de metas da Seeduc-RJ, e acaba por ser incorporado de forma irrefletida pela escola.

Ao comparar a normativa de avaliação adotada nas escolas investigadas, destaca-se que, mesmo demonstrando certa atenção aos processos educativos informais e manifestando a necessidade de uma avaliação para além da prova, os professores apoiam suas avaliações essencialmente nos testes objetivos: são 70\% da nota discente concebida a partir das avaliações sistematizadas em provas objetivas 
(Saerj/Saerjinho e Provão). Mesmo, teoricamente, seguindo a normativa com a adoção de três instrumentos de avaliação, o princípio da diversidade dos instrumentos não é contemplado, pois há um peso muito grande para os testes objetivos. O preceito avaliativo da diversificação dos instrumentos está baseado na construção de uma visão holística da aprendizagem dos alunos, o que não se configura nas práticas escolares.

Ressalta-se que "[...] a avaliação de que precisamos deve usar de processos variados: provas, entrevistas, relatórios, portfólios, dossiês, autoavaliação, avaliação coletiva, registros e etc.” (TEIXEIRA; NUNES, 2008, p. 168), e assim contemplar a utilização de diferentes linguagens: escrita, oral, visual, gráfica, estética, poética e outras formas de comunicação, de modo a permitir ao aluno o melhor meio de expressão de suas aprendizagens e que a avaliação escolar cumpra seu papel de reorientação da prática educativa.

Diante da observação da adoção de uma normativa de avaliação idêntica entre as escolas investigadas, podemos inferir que é uma postura passível de questionamentos, na medida em que, indiferenciadamente, consta dos projetos político-pedagógicos (PPP) de unidades escolares inseridas em contextos distintos, mas, ainda assim, acordada entre professores e gestores. O PPP é um documento que expressa as intenções e o trabalho realizado por toda a equipe escolar para atender às diretrizes nacionais e às necessidades específicas da comunidade escolar (SILVA, 2011). Considerando a realidade municipal, dentre 39 escolas estaduais, encontrar duas unidades escolares que adotam a mesma normativa de avaliação, em contextos distintos, requer atenção, na medida em que essa realidade avaliativa também foi identificada em escolas fora da amostra. Tal fato motiva questionamentos sobre a padronização avaliativa como estratégia de controle da avaliação do processo ensino-aprendizagem, que incide diretamente no fluxo escolar (aprovação, reprovação e repetência) e que, por consequência, é um indicador que compõe os índices do Iderj e do Ideb.

Quando as escolas assumem o Provão como instrumento de avaliação com peso de $50 \%$ da nota discente, questiona-se o que esse modelo de avaliação efetivamente avalia. Observa-se que uma prova objetiva, composta por um limitado número de questões (duas ou três, em média) de cada disciplina, não tem condições de expressar o nível de aprendizagem do aluno. Identifica-se a necessidade de verificar o conhecimento global dos alunos, que pode ser contemplado por meio de uma "prova integrada" num período determinado e com uma elaboração adequada. Entretanto, na prática, o modelo de avaliação adotado pelas escolas acaba por valorizar o quesito "sorte", em detrimento de conhecer os processos de aprendizagem efetivados pelos alunos.

De acordo com Horta Neto (2007), o acompanhamento diário do professor com atividades paralelas, caderno e outros instrumentos citados tende a aproximar a 
realidade do aprendizado e propicia decisões sobre a avaliação do aluno. Todavia, na realidade investigada, esses instrumentos pesam apenas $30 \%$ da nota discente. Nota-se que a reprodução do modelo Saerj/Saerjinho no Provão efetiva um nítido modelo de preparação para as avaliações externas, reconfigurando a avaliação escolar. Arcas (2009) alerta que as avaliações internas tendem a espelhar as avaliações externas, invertendo o processo de avaliação, a fim de atender às demandas externas, reduzindo a atividade pedagógica escolar.

Gilson (2012) destaca que os "simulados” foram adotados como uma das estratégias para superar as dificuldades de realização do Saerjinho, com a justificativa de que também são adotados por escolas da rede particular como preparatório das avaliações externas, como a Prova Brasil e o Exame Nacional do Ensino Médio (Enem). Nessa perspectiva, associa-se o simulado ao Provão, o que ratifica a perspectiva de que não é um instrumento utilizado apenas nas escolas investigadas.

Outra questão associada à adesão ao Provão como padrão avaliativo é destacada por Perrenoud e Thurler (2007) quando afirmam que, no momento em que é imposta uma avaliação externa, obviamente a escola será constrangida a apresentar uma coerência total entre as avaliações internas e externas. Esse processo ocorre porque a escola supervaloriza as medidas que precedem de instâncias superiores, alegando sua maior confiabilidade, ao passo que não tem subsídios suficientes para contestar ou apresentar alternativas, o que pode estar associado à própria fragilidade da formação docente.

Ressalta-se que a portaria de avaliação imputa a obrigatoriedade do instrumento de avaliação Saerjinho e delega a responsabilidade avaliativa na perspectiva qualitativa ao professor, que deve elaborá-la atendendo a seus objetivos educativos. A incorporação da normativa de avaliação adotada pelas escolas investigadas acaba por sistematizar burocraticamente a avaliação escolar: "avaliocracia” (CORREIA, 2010; CORREIA; FIDALGO; FIDALGO, 2011).

Pensar num cenário alternativo de avaliação é possível, na medida em que a obrigatoriedade legal é imputada ao uso de apenas um instrumento de avaliação, sem a definição sobre sua quantificação. Constata-se que não há resistência dos professores às normativas legais de avaliação, tampouco uma postura crítica diante dos processos avaliativos instituídos em nível escolar. Pressupõe-se que a escola não tem refletido sobre as políticas públicas de avaliação escolar e sequer vislumbra as limitações avaliativas na prática docente. Também é necessário considerar a questão do constrangimento gerado pela não adesão à normativa (PERRENOUD; THURLER, 2007), em que o professor é coagido pelos demais atores, na medida em que venha apresentar uma perspectiva diferenciada da maioria de seus pares, por exemplo. O constrangimento transparece de maneira pública e explicitamente exposta no website da Seeduc-RJ em relação à adesão ao Saerjinho: 
A Secretaria não lançou apenas as metas. Está subsidiando e acompanhando. Isso é o Saerjinho. E ganha o bônus toda a equipe de cada escola. Não é individual. Tudo para que o trabalho seja realizado em equipe. Portanto, não participar do Saerjinho prejudica a equipe escolar e o aluno. ${ }^{5}$

Nota-se um tom coercitivo e constrangedor no texto da Secretaria de Educação que imputa toda a responsabilidade do bônus, uma vinculação direta àquele que não participar do Saerjinho. No caso das escolas investigadas, o mesmo constrangimento pode ser estendido à adesão do professor ao Provão, que passa por avaliação interna do processo ensino-aprendizagem, mas, na verdade, constitui um instrumento que atende ao indicador fluxo que compõe o índice pelo qual a escola pode ser bonificada. Melo e Lima (2016) e Ravitch (2011) destacam que a política de responsabilização dos profissionais da educação pelo mau desempenho dos estudantes foi o grande legado deixado pelos investimentos em avaliações nos últimos anos.

Simultaneamente, coexistem, entre os agentes escolares, a postura acrítica ao sistema avaliativo adotado e o constrangimento gerado contra quaisquer posturas diferenciadas, justamente porque há a vinculação direta do bônus à avaliação. Como consequência, observa-se a reprodução dos pressupostos da avaliação externa no ambiente escolar, endossada por gestores e professores e replicada no contexto de avaliação escolar, a qual demanda outra postura didático-pedagógica.

De acordo com as assertivas dos professores em relação aos objetivos de sua avaliação escolar, é possível observar o objetivo de verificação de aprendizagem, conferência de conteúdo, aquisição de conhecimento.

\section{Ah, para ver se o aluno adquiriu o conhecimento necessário, né? Que aqui- lo que a gente passou foi adquirido pelo aluno. (Professor de Matemática, Escola A). \\ Verificação do aprendizado dos conteúdos. (Professor de Geografia, Escola A).}

De acordo com a finalidade de avaliação apresentada pelos professores da Escola $A$, identificamos a adoção do modelo classificatório com objetivo de verificar resultados de aprendizagem dos alunos, com ênfase no processo burocratizado da avaliação, que se cumpre em obediência ao sistema adotado.

\footnotetext{
É pra escola é... estabelecer o número exigido pelo sistema educacional estadual. (Professor de Língua Portuguesa, Escola A).

Pra ver se o aluno entendeu, mas também porque a gente tem que cumprir a questão da quantidade de avaliações. (Professora de Educação Física, Escola A).
} 
No que concerne à perspectiva dos professores da Escola $B$, novamente encontra-se a predominância do modelo classificatório como principal objetivo da avaliação, como manifestação de aspectos que podem remeter a uma avaliação formativa, porém em dissonância com o modelo avaliativo praticado.

Avalio pra ver o que eles estão aprendendo do conteúdo que eu estou ensinando e que eles precisam. (Professor de Língua Portuguesa, Escola B). Pra saber se ele alcançou aquilo que eu ensinei. (Professor de Matemática, Escola B).

O processo de burocratização avaliativa também é identificado na Escola $B$, assim como já observado na Escola $A$.

Meus objetivos são que a gente tenha uma avaliação. Nós somos cobra-
dos por essa avaliação. Por mais que a gente queira fazer uma avaliação
subjetiva para o aluno, a gente tem que ter uma avaliação que seja quan-
titativa, em números. (Professora de Biologia, Escola B).

Ressaltam-se a predominância do modelo classificatório da avaliação e a burocratização excessiva do processo avaliativo, além da passividade destacada pela professora de Biologia, em que os objetivos de avaliação se restringem à operacionalização da avaliação, ignorando-se os objetivos educativos inerentes à prática avaliativa.

Ao observar o modelo de avaliação adotado pelos professores investigados nas escolas A e B, nota-se a consolidação de um modelo normativo classificatório, com ênfase nos aspectos burocráticos, justificado pela adoção dos instrumentos de avaliação objetivos, testes padronizados que valorizam os resultados.

A burocratização ficou clara nos discursos apresentados como uma resposta ao sistema, não permitindo ou constrangendo uma postura crítica diante do processo de avaliação, soando mais como aceitação dos procedimentos de avaliação do processo ensino-aprendizagem adotados, seguidos e consumados. Dias Sobrinho (2004, p. 718) afirma que,

[...] quando a avaliação é apropriada pelas instâncias de poder, sem uma interlocução com os educadores, enfraquece sua potencialidade formativa em favor das funções burocráticas, controladoras e economicistas.

Há o desejo de fazer algo diferente. Entretanto, a aceitação fatalista do modelo avaliativo supera uma atitude crítica em relação à avaliação, reproduzindo o imposto pelo sistema.

Cada modelo de avaliação escolar demanda objetivos e instrumentos específicos. Se a avaliação escolar está fundamentada em instrumentos objetivos, de cunho 
quantitativo, denota um processo de verificação da aprendizagem que caracteriza o modelo de avaliação predominantemente classificatório.

Podemos afirmar que esse modelo de avaliação adotado pelas escolas A e B está coerente com o objetivo de avaliação apresentado pelos professores, a verificação da aprendizagem dos alunos. Todavia, a adoção de uma normativa unificada (Saerjinho $20 \%$, Provão 50\%, outros 30\%) e um único modelo de avaliação (classificatório) não contempla o processo ensino-aprendizagem como um todo, dissociando a ideia de monitoramento de qualidade inicialmente disseminada como objetivo de ser do Saerj. Desconsiderar o modelo diagnóstico ou desvalorizar os modelos formativos e mediadores não contempla os objetivos para a efetiva aprendizagem enquanto processo, tampouco contribui para o aprimoramento da tão almejada qualidade.

Ressalta-se que, diante da normativa e do modelo de avaliação adotados pelas escolas investigadas, aqueles utilizados majoritariamente são os que associam a atribuição de notas ao ato de avaliar. Luckesi (2002, p. 5) aponta como equívoco a vinculação de nota à avaliação.

É comum ouvir expressões, tais como: "Na avaliação, meus alunos não foram muito bem; em média, obtiveram notas entre 5 e 6". As notas cinco e seis, em si, não têm nada a ver com avaliação, mas com registro de resultados em documentos oficiais.

A necessidade de apresentação de números positivos em resposta ao sistema avaliativo da rede estadual faz com que o professor utilize, exclusivamente, a nota como elemento embasador da avaliação escolar. Entretanto, a nota não tem, necessariamente, a propriedade de representar a aprendizagem do aluno, sendo tão somente um registro quantitativo que não pode ser associado à qualidade da aprendizagem, tampouco subsidiar o processo ensino-aprendizagem. Pode, sim, ser utilizado como mais um dado a ser analisado.

O autor também destaca, como equívoco, a utilização de exames para realizar uma avaliação. "O ato de avaliar tem seu foco na construção dos melhores resultados possíveis, enquanto o ato de examinar está centrado no julgamento de aprovação ou reprovação" (LUCKESI, 2002, p. 4). Nessas palavras, percebe-se a distinção entre examinar e avaliar, frequentemente vistos na esfera escolar como sinônimos, conforme se ratifica nos dados analisados entre os professores e escolas investigados.

Tal fato ocorre porque professores projetam suas representações sociais ${ }^{6}$ sem questioná-las, reproduzindo um modelo avaliativo externamente configurado,

6 No sentido atribuído por Luckesi (2002, p. 1) ao entender que as representações sociais "são modos inconscientes de compreender um determinado fenômeno ou uma determinada prática existencial, individual ou coletiva, que se expressam por meio de falas cotidianas, crenças, provérbios, modos de agir, que podem estar vinculados ao passado, ao presente ou ao futuro". 
sem observar sua coerência. Dessa forma, ressalta-se a necessidade de um olhar introspectivo do professor em relação às representações sociais da avaliação reproduzidas no ambiente escolar que reiteram um modelo de avaliação que pouco está associado à qualidade da aprendizagem.

\section{CONSIDERAÇÕES FINAIS}

Diante do modelo de avaliação adotado pelas escolas investigadas, constata-se que, apesar de diferentes localizações e comunidades, de professores e gestores distintos, ainda assim, os critérios, instrumentos e metodologias de avaliação se mostraram idênticos nas duas escolas. A padronização avaliativa identificada denota uma maneira de controle do fluxo (aprovação, reprovação e evasão), enquanto indicador que compõe o Iderj e o Ideb e, consequentemente, a produção de índices que não necessariamente são oriundos das aprendizagens dos alunos, mas de treinos para testes, implicando diretamente na avaliação escolar.

Notou-se, declaradamente, entre os docentes, o desejo de se fazer algo diferente, próximo da demanda de aprendizagem dos alunos, mas a aceitação do modelo avaliativo e o constrangimento que envolve os professores, nas esferas política e organizacional da avaliação externa, geram a reprodução do sistema que impacta diretamente na organização da avaliação escolar, com a finalidade de verificação da aprendizagem. Mesmo que a sensação de violação pedagógica esteja latente, os números e índices produzidos pelas avaliações externas conformam, particularmente, aos agentes de escolas bonificadas.

Diante da predominância do modelo classificatório de avaliação, ainda que muito criticado por seu caráter reducionista da aprendizagem e estanque, prevalece a adoção maciça dos testes objetivos, conduzindo, assim, a avaliação escolar para a estandardização de notas e critérios enrijecidos, desalinhada do processo ensino-aprendizagem.

\section{REFERÊNCIAS}

AFONSO, Almerindo Janela. Estado, políticas educacionais e obsessão avaliativa. Contrapontos, Itajaí, SC, v. 7, n. 1, p. 11-22, jan./abr. 2007.

ARCAS, Paulo Henrique. Implicações da progressão continuada e do SARESP na avaliação escolar: tensões, dilemas e tendências. 2009. 178 f. Tese (Doutorado em Educação) - Programa de Pós-Graduação em Educação, Faculdade de Educação da Universidade de São Paulo, São Paulo, 2009.

BERTAGNA, Regiane Helena; BORGHI, Raquel Fontes. Sistemas de avaliação dos estados no Brasil: avanços do gerencialismo na educação básica. Revista Teias, Rio de Janeiro, v. 19. n. 54, p. 48-62, jul./set. 2018. 
BRASIL. Ministério da Educação. Conselho Nacional de Educação. Câmara de Educação Básica. Resolução n. 24, de 30 de janeiro de 2012. Define Diretrizes Curriculares Nacionais para o Ensino Médio. Diário Oficial da União, Brasília, DF, 30 jan. 2012. Disponível em: http://portal.mec.gov.br/ index.php?option=com_docman\&view=download\&alias=9864-rceb002-12\&category_slug=janeiro2012-pdf\&Itemid=30192. Acesso em: 12 jan. 2014.

CORREIA, José Alberto. La "evaluocracia”: el papel de la evaluación en la legitimación y reconstrucción institucional de la educación. Avances en Supervisión Educativa, Madrid, n. 13, p. 1-9, out. 2010.

CORREIA, José Alberto; FIDALGO, Fernando; FIDALGO, Nara Rocha. A avaliação como trabalho e o trabalho da avaliação. Educação, Sociedade \& Culturas, Porto, n. 33, p. 37-50, 2011.

DIAS SOBRINHO, José. Avaliação ética e política em função da educação como direito público ou como mercadoria? Educação e Sociedade, Campinas, SP, v. 25, n. 88 (n. especial), p. 703-725, out. 2004.

GILSON, Rosane de Bastos Alves. Saerjinho: desafios e conquistas na busca por uma educação de qualidade para o estado do RJ. 2012. 110 f. Dissertação (Mestrado Profissional em Gestão e Avaliação da Educação Pública) - Programa de Pós-Graduação Profissional, Universidade Federal de Juiz de Fora, Juiz de Fora, 2012.

HADJI, Charles. Avaliação desmistificada. Porto Alegre: Artmed, 2001.

HOFFMANN, Jussara. Avaliação: mito \& desafio - uma perspectiva construtivista. Porto Alegre: Mediação, 2006.

HORTA NETO, João Luiz. Um olhar retrospectivo sobre a avaliação externa no Brasil: das primeiras medições em educação até o SAEB de 2005. Revista Iberoamericana de Educación, Madri, v. 42, n. 5, p. 1-14, abr. 2007.

LUCKESI, Cipriano. Avaliação da aprendizagem na escola e a questão das representações sociais. Eccos Revista Cientifica, São Paulo, v. 4, n. 2, p. 79-88, 2002.

MACHADO, Cristiane; ALAVARSE, Ocimar Munhoz. Responsabilização ou controle da qualidade do ensino: a que serve a avaliação externa? Educação: Teoria e Prática, Rio Claro, SP, v. 25, n. 48, p. 67-79, jan./abr. 2015.

MARINHO, Paulo; LEITE, Carlinda; FERNANDES, Preciosa. A avaliação da aprendizagem: um ciclo vicioso de "testinite". Estudos em Avaliação Educacional, São Paulo, v. 24, n. 55, p. 304-334, abr./ago. 2013.

MARTINS, Leane Rodrigues. Três pontos de vista sobre avaliações em larga escala no município de Duque de Caxias: governo, escolas e sindicatos. 2015. 129 f. Dissertação (Mestrado em Educação) - Programa de Pós-Graduação em Educação, Universidade Federal do Rio de Janeiro, Rio de Janeiro, 2015.

MELO, Eliane Pimentel Camillo Barra Nova de; LIMA, Paulo Gomes. O estado brasileiro e as políticas de avaliação da educação. Laplage em Revista, Sorocaba, SP, v. 2, n. 2, p. 111-128, maio/ago. 2016.

PERRENOUD, Philippe; THURLER, Monica Gather. As competências para ensinar no século XXI: a formação dos professores e o desafio da avaliação. Porto Alegre: Artmed, 2007. 
RAVITCH, Diane. Vida e morte do grande sistema escolar americano: como os testes padronizados e o modelo de mercado ameaçam a educação. Porto Alegre: Sulina, 2011.

RIO DE JANEIRO (Estado). Governo do Estado do Rio de Janeiro. Comissão de Educação, Cultura e Desportos. Lei n. 4.528, de 28 de março de 2005. Estabelece as diretrizes para a organização do sistema de ensino do Estado do Rio de Janeiro. Diário Oficial do Estado do Rio de Janeiro, Rio de janeiro, 29 mar. 2005.

RIO DE JANEIRO (Estado). Secretaria de Estado de Educação. Portaria Seeduc/Sugen n. 419, de 27 de setembro de 2013. Estabelece normas de avaliação do desempenho escolar e dá outras providencias. Diário Oficial do Estado do Rio de Janeiro, Rio de Janeiro, p. 30, 27 set. 2013.

RIO DE JANEIRO (Estado). Secretaria de Estado de Educação. Decreto n. 5.092, de 28 de abril de 2014. Regulamenta a bonificação por resultado, instituída pelo Decreto n. 44.716 , de 7 de abril de 2014, que conferiu nova redação ao Decreto n. 44.281, de 1 de julho de 2013, que conferiu nova redação ao Decreto n. 42.793, de 6 de janeiro de 2011, e dá outras providências. Diário Oficial do Estado do Rio de Janeiro, Rio de Janeiro, p. 16, 30 abr. 2014.

SILVA, Janssen Felipe. Avaliação na perspectiva formativa-reguladora: pressupostos teóricos e práticos. Porto Alegre: Mediação, 2011.

STAKE, Robert E. Pesquisa qualitativa/naturalista: problemas epistemológicos. Educação e Seleção, São Paulo, n. 7, p. 19-27, jun. 1983.

TEIXEIRA, Josele; NUNES, Liliane. Avaliação escolar: da teoria à prática. Rio de Janeiro: WAK, 2008.

TERRASÊCA, Manuela. Autoavaliação, avaliação externa: afinal para que serve a avaliação das escolas? Cadernos Cedes, Campinas, SP, v. 36, n. 99, p. 155-174, maio/ago. 2016.

YIN, Robert K. Estudo de caso, planejamento e métodos. 2. ed. São Paulo: Bookman, 2001.

\section{COMO CITAR ESTE ARTIGO}

ALVERNAZ, Aline; SOUZA, Nádia M. P.; HENRIQUE, José. Avaliação externa: implicações na avaliação escolar. Estudos em Avaliação Educacional, São Paulo, v. 32, e06778, 2021. DOI: https://doi. org/10.18222/eae.v32.6778

Recebido em: 28 AGOSTO 2019

Aprovado para publicação em: 7 OUTUBRO 2021

Este é um artigo de acesso aberto distribuído nos termos da licença Creative Commons do tipo BY-NC. 